\title{
Preterm Gestation Along with Partial Hydatidiform Mole and Alive Foetus
}

\author{
Tamrakar SR, Chawla CD.
}

Department of Obstetrics and Gynecology

Dhulikhel Hospital - Kathmandu University Hospital

Dhulikhel, Nepal

\section{CORRESPONDING}

Suman Raj Tamrakar

Department of Obstetrics and Gynaecology

Dhulikhel Hospital - Kathmandu University Hospital

Dhulikhel, Nepal.

E-mail: drsuman537@yahoo.com

Citation

Tamrakar SR, Chawla CD. Preterm gestation along with partial hydatiform mole and alive foetus. Kathmandu Univ Med J 2011;35(3):222-4.

\begin{abstract}
Gestational trophoblastic disease encompasses a diverse group of lesion. If molar changes in the placenta are known along with an alive fetus then the situation is difficult to manage. We present successfully managed case of partial degeneration of placenta in molar pregnancy with an alive fetus at second stage of preterm labour.
\end{abstract}

\section{KEY WORDS}

B hCG, Partial mole, preterm labour,

\section{INTRODUCTION}

Gestational trophoblastic disease consists of a broad spectrum of conditions ranging from an uncomplicated partial hydatidiform molar pregnancy to stage-IV choriocarinoma with cerebral metastases. The modified World Health Organization classification of gestational trophoblastic disease includes complete and partial hydatidiform mole, invasive mole, choriocarinoma, placental site trophoblastic tumour, epitheloid, trophoblastic tumor, exaggerated placental site and placental site nodules. The usual management of gestational trophoblastic disease is evacuation of the uterus and follow up because of higher chances of patient to develop choriocarinoma. ${ }^{1}$ But some time when molar change is there in the placenta along with an alive fetus then expectant management can be performed under strict surveillance. ${ }^{2,3}$ We present a case who was diagnosed to have partial hydatidiform mole alongwith alive fetus in early third trimester and was referred to us at second stage of preterm labour.

\section{CASE REPORT}

A 26 years old lady who was $(\mathrm{G} 2 \mathrm{P} 1+0)$ was referred from nearby hospital at second stage of labour with gestational amenorrhea of 31 weeks with history of labour pain of 12 hours.Previously she had one supervised uncomplicated pregnancy and delivered live baby at term. Her postnatal period was uneventful. Her periods were regular previously. In this pregnancy, she had regular antenatal care at Primary Health Care Clinic (PHCC) in Bhartapur and Banepa. She didn't give history of vaginal bleeding, excessive vomiting, lower abdominal pain and other features suggestive of molar pregnancy except she was told to have uterine size larger than gestational age.

Obstetrical ultrasound (at 24 weeks) showed normal single live fetus of 27 weeks, adequate liquor, without any theca lutein cysts and grade I placenta with calcification and thickness of $81.3 \mathrm{~mm}$. But she was not suspected to have molar pregnancy hence $\beta$ hCG (serum and/or urine) was not done. She was on iron and calcium prophylaxis. Her blood group was $\mathrm{O}$ positive and her haemoglobin level was $10.3 \mathrm{gm} \%$.

At 30 weeks on her second antenatal visit, she was told to repeat obstetrical ultrasound. One week later repeat ultrasound showed single live fetus of 32 weeks with placental changes suggestive of partial mole.On the 


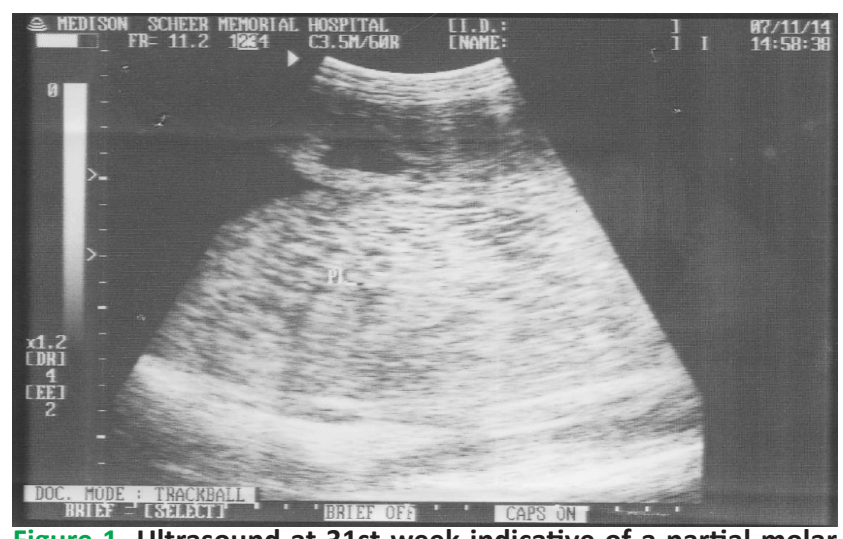

Figure 1. Ultrasound at 31st week indicative of a partial molar pregnancy.

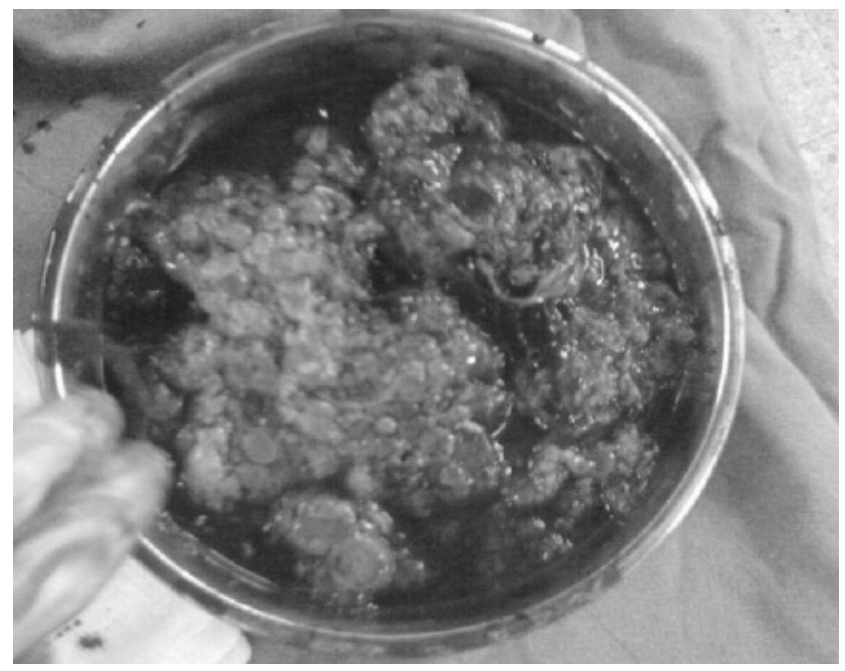

Figure 2. Gross appearance of the molar tissue.

same evening she went into spontaneous labour and attended nearby hospital but she was referred to us for further management and NICU care. She arrived in the emergency room with 12 hours of labour pain. Her vitals were normal. On examination her uterine height was more than gestational age, felt doughy and fetal heart sound was hardly audible. USG showed an alive foetus with partial mole. Internal findings showed fully dilated cervical os and membranes were present. Labour monitored normally and partogram was maintained. After 30 minutes she delivered a male baby of 1100 gram with satisfactory APGAR score. Placenta was delivered by Brandt's Andrews method. Third stage of labor managed with oxytocics. Weight of the placenta was 250 gram and that of molar tissues was 350 gram.

Additional investigations (RFT, LFT, chest x-ray coagulation profile) done after delivery were normal. After two weeks following delivery her urine pregnancy test was positive but it was negative in 1: 50 titre. The mother was transfused one pint of crossmatched blood. Check scan done on 1st day of puerperium showed minimal retained molar tissues hence suction evacuation was done under IV anaesthesia in operation theatre. Histopathology of placenta showed features of partial mole. Chromosomal study of placenta was not performed.

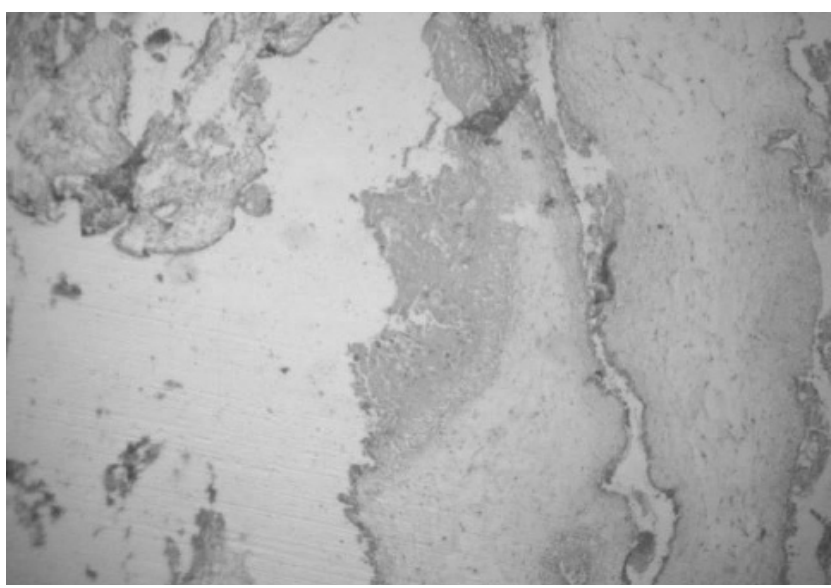

Figure 3. Partial Hyaditiform mole on histopathology.

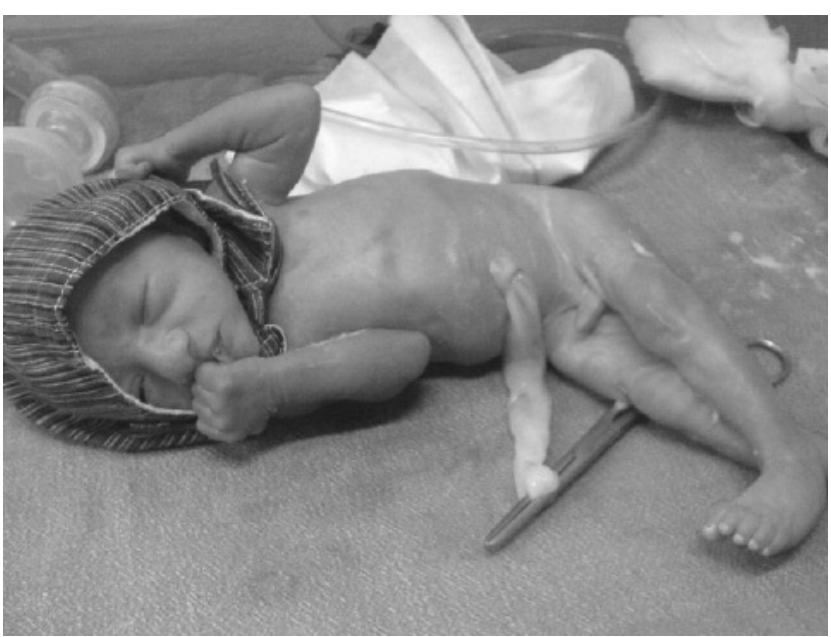

Figure 4. Alive baby born.

The baby was admitted in NICU in view of prematurity. In the mean time he developed neonatal sepsis and hyperbilirubinaemia and managed appropriately. He gradually improved and discharged on 24th day of admission.

The patient was being followed up weekly with urinary $\beta$ hCG test ( to rule out placental site trophoblastic tumor and choriocarinoma) as we do not have facility of serum $\beta$ hCG in our hospital. Urine pregnancy test was negative in 3 weeks following delivery. On her regular follow up repeat ultrasound didn't show features suggestive of myometrial invasion. The mother and the baby both were fine after five years of delivery.

\section{DISCUSSION}

Hydatidiform mole coexistent with a twin live fetus is a rare entity, occurring in $0.005-0.01 \%$ of all pregnancies. Such condition has risk of preterm delivery as obvious from the current case report and previously reported cases. Zhang P et al from University of California San Diego reported partial molar pregnancy with dead fetus in utero at 26 weeks. ${ }^{4}$ Zahida P et al in Pakistan, reported G4P1+2 lady with partial hydatidiform mole along with alive baby managed conservatively 18 weeks onwards and delivered successfully at term. ${ }^{5}$ Bruchim I et al reported a case of lady 
with partial mole at 41 weeks of gestation and another at 26 weeks with complete hydatidiform mole along with twin fetuses. ${ }^{6}$ Such patients have risk of developing persistent gestational trophoblastic disease.

Though some authors questioned the follow up of patient with partial hydatidiform mole by serum bhCG, such patients should be followed up at regular interval. Patient with molar pregnancy can develop choriocarcinoma and mortality has been reported by Seckl et al. ${ }^{7}$ However partial hydatidiform mole rarely requires chemotherapy.

\section{CONCLUSION}

Though molar pregnancy coexistent with a live fetus is a rare event, such case presented to us at second stage of preterm labour was managed successfully with multidisciplinary approach of Obstetrician, Paediatrician and Nursing staffs. Both mother and baby were followed up till five years after delivery and it was uneventful.

\section{REFERENCES}

1. Hancock BW, Tidy JA. Current management of molar pregnancy. J Reprod Med 2002; 47(5): 347 -54.

2. Berkowitz RS, Tuncer ZS, Bernstein MR, Goldstein DP. Management of Gestational Trophoblastic disease. Subsequent pregnancy experience. Semin Oncol 2000; 27(6):678-85.

3. Shapter AP, McLellan R. Gestational Trophoblastic disease. Obstet Gynecol Clin North Am 2001; 28(4): 805-17.

4. Zhang P, McGinniss MJ, Sawai S, Benirschke K. Diploid / triploid mosaic placenta with fetus. Towards a better understanding of partial moles. Early Hum Dev 2000; 60(1):1-11.

5. Zahida P, Rubina B, Taimur J, Iftikhar Q. Partial Hydatidiform Mole along with term gestation and alive baby. J Ayub Med Coll Dec 2004;16(4):84-5.

6. Bruchim I, Kidron D, Amiel A, Altaras M, Fejgin MD. Complete hydatidiform mole and a coexistent viable fetus. Report of two cases and review of the literature. Gynecol Oncol 2000; 77(1): 197-202

7. Seckl MJ, Fisher RA, Salerno G, Rees H, Paradinas FJ, Foskett M, Newlands ES. Choriocarcinoma and partial hydatidiform moles. Lancet.2000;356(9239):36-9. 